\title{
DO ISIHURI AO WARADZU: 0 QUE AS IDEOLOGIAS XAVANTE DE CONCEPÇ̃̃O, SUBSTÂNCIA E FORMACÃO DA PESSOA NOS DIZEM SOBRE O ESTATUTO ONTOLÓGICO DO OUTRO?
}

\author{
Estevão Rafael Fernandes \\ Universidade Federal de Rondônia - Brasil
}

Resumo: Este trabalho busca fazer uma ponte entre as noções de concepção, substância e pessoa nos índios xavante, do Mato Grosso (e, de um modo geral, nos Jê), e sua percepção da alteridade. O que demonstro é que tais noções, apesar de parecerem, em sua essência, estáticas, são extremamente dinâmicas - sendo que tal dinamismo reflete uma ideologia de percepção inclusiva do Outro para além da corporalidade, mas também em sua mitologia, história e no contato interétnico.

Palavras-chave: corporalidade, indios jê, pessoa, Xavante.

Abstract: This work reflects about the notions of conception, substance and personhood among the the Shavante Indians (and between the Gê Indians, in general) and its perception of the Other. What I try to demonstrate is that such notions, although it seems to, are not static, but extremely dynamic - being that such dynamism reflects an ideology of inclusive perception of this "Other", beyond bodiness, but also in its mythology, history and in the contact with the whites.

Keywords: bodiness, Gê speaking Indians, personhood, Shavante.

Um bom ponto de partida para se tratar da corporalidade xavante é o momento da concepção da criança. Giaccaria e Heide (1984, p. 230-231) fazem uma descrição detalhada de como se dá o ritual. Em primeiro lugar, o ato sexual entre o casal deve dar-se em local coberto, seja esse a casa ou o abrigo utilizado pelos Xavante durante a estação de caça. Além disso, o ato somente pode ocorrer entre meia-noite e o nascer do sol, sendo que cabe à mulher tomar a iniciativa sobre querer ter filhos. Feito isso, o marido pergunta-lhe 
de que sexo quer a criança para, no dia seguinte, preparar brincos de madeira especificamente pintados para este ou aquele sexo - não apenas os brincos seriam diferentes, como também a posição adotada durante o coito, para o caso de se querer filhos homens ou mulheres, bem como a forma como o filho é solicitado aos espíritos, dañimite. No mesmo trecho, Giaccaria e Heide (1984, p. 231) já nos trazem uma indicação para algo que será recuperado adiante, a noção de substância:

No caso de uma mulher não conseguir ter filhos, o marido pede a outro homem (geralmente o irmão) que se una a ela. O filho seria considerado legítimo do marido, não do verdadeiro pai. Por este costume, pode ser que se tenha a conviç̧ão de que a esterilidade seja sempre atribuída ao homem. A mulher seria sempre fecunda.

Ainda sobre a noção de substância, Maybury-Lewis (1984, p. 108-109), em sua detalhada descrição do nascimento, nos traz informações interessantes:

As [medidas que garantem a concepção] mais comuns são as relações sexuais repetidas, o uso de batoques auriculares (pintados de vermelho) durante as relações e a manipulação de um pó conhecido como wede dzu (wede = madeira e $d z u=$ pó $\left.^{1}\right)$. [...] O significado simbólico dos batoques auriculares é também discutido adiante. Aqui, basta dizer que os Xavante pensam o batoque auricular cilíndrico que fura o lóbulo da orelha de um homem como equivalente ao seu pênis ao perfurar uma mulher. Isto se dá a partir do momento em que o rapaz atinge a maturidade. Batoques auriculares pintados de vermelho têm, assim, propriedades procriativas especiais quando associados ao ato sexual. Os Xavante, portanto, entendem claramente a relação entre o coito e a concepção. Parecem, no entanto, conceber a formação da criança como um processo induzido por relações sexuais repetidas. Por duas vezes alguns homens explicaram-no a mim deste modo: "tsihuri, tsihuri, tsihuri, tsihuri, tsihuri ahödi. Tsihuri, tsihuri, tsihuri waptãrã" (copular, copular, copular, copular, copular muito. Grávida. Copular, copular, copular, nasce). Eles ilustravam o processo contando nos dedos, de modo que "grávida" caía no quinto dedo e "nasce" no nono. Outros Xavante contaram que o pai "faz seu filho" por meio de intercurso sexual repetido com a mãe. Parece, portanto, que acreditam que um homem forma a criança

1 Segundo informação obtida por Brito Vianna (2008, p. 268), o sufixo $d z u$ equivale a "aquilo que se renova, como as cobras, que trocam de pele", como veremos mais à frente.

Horizontes Antropológicos, Porto Alegre, ano 16, n. 34, p. 453-477, jul./dez. 2010 
durante os primeiros meses da gestação e que a criança está totalmente "feita" (e a mulher, portanto, propriamente "grávida" apenas por volta do quinto mês, o que coincide com o tempo em que a sua condição é indubitavelmente aparente.

Dois esclarecimentos aqui parecem importantes antes de seguirmos adiante na descrição de Maybury-Lewis acerca das ideias xavante de concepção. A primeira diz respeito à associação batoque = aptidão a "perfurar" a mulher; a segunda, quanto à ideia de substância (como se pode perceber na ideia de coito contínuo para a formação do feto), presente em boa parte da etnologia jê sobre o assunto.

Não é por acaso que Maybury-Lewis (1984) associe o uso dos brincos a uma potência sexual, ainda que, segundo penso, o que ele escreve não possa ser levado tão ao pé da letra. Vimos o trecho no qual o autor escreve que "basta dizer que os Xavante pensam o batoque auricular cilíndrico que fura o lóbulo da orelha de um homem como equivalente ao seu pênis ao perfurar uma mulher" (Maybury-Lewis, 1984, p. 108). Mais à frente, o autor retoma o tema:

Esses batoques cilíndricos perfuram os lóbulos das orelhas dos iniciandos do mesmo modo que seu pênis, dizem os Xavante, pode agora penetrar uma mulher. A perfuração das orelhas simboliza, portanto, o reconhecimento de sua condição de homens plenos. Segundo o pensamento convencional dos Xavante, os meninos são vistos como sexualmente capazes a partir do momento em que entram para a casa dos solteiros e passam a usar estojos penianos. Só ao receberem batoques auriculares, porém, é que passam à condição plena de homens, ou seja, só a partir desse momento estão socialmente autorizados a exercer sua potência sexual. (Maybury-Lewis, 1984, p. 314).

Penso que talvez a utilização dos batoques fosse mais bem entendida se trocássemos a frase "condição plena de homens" para "condição de pessoas plenas", e o digo à luz tanto da bibliografia xavante quanto jê. Lopes da Silva (1980, f. 51 e seguintes), por exemplo, demonstra como, após a iniciação (ou seja, a furação das orelhas), jovem receberá seu primeiro nome de adulto. No entanto, dizer que ele se torne uma pessoa plena não implica que socialmente ele esteja "maduro", posto que a pessoa social xavante está em permanente devir no que diz respeito aos papéis que ocupa - a própria tese de Lopes da Silva (1980), por exemplo, trata de demonstrar isso. O batoque, de certa forma, mimetiza a plenitude da personitude xavante, o que explica 
seu uso nos rituais de concepção. Autores como Graham (1995), Eid (2002) e Fernandes (2005) destacaram como o princípio básico da cosmologia xavante é o da transformação, sendo a pessoa xavante uma replicação formal desse processo: o Xavante, que nasce sem nome, sem classe de idade e tampouco amigos formais, se torna uma pessoa no sentido pleno do termo, capaz de interferir ativamente nos rumos de sua comunidade. Em determinado nível de representação, o batoque auricular mimetiza tal princípio transformacional e a capacidade para exercê-lo - nesse sentido, é emblemático que justamente as crianças (ainda não pessoas plenas xavante) sejam aquelas para as quais as amebas, vírus e bactérias se direcionem e aquelas mais suscetíveis às doenças por eles causadas, segundo os depoimentos ouvidos por mim, ao longo de trabalho de campo.

Evidentemente não é o propósito aqui buscar uma análise simbólica detalhada do uso dos batoques auriculares pelos Xavante: por mais tentador que tal caminho se prefigure, ele nos desviaria (e muito) do foco - buscar demonstrar: 1) o porquê de serem os batoques utilizados nos rituais de concepção; e 2) o que eles nos dizem sobre as noções xavante de corporalidade. Assim, até aqui, temos que os batoques simbolizem: a) a capacidade masculina de penetração; b) como consequência, eles representam o pênis; c) representam, ainda, o poder de transformação que caracteriza a sociedade xavante: os adolescentes agora são pessoas com nomes e papéis socialmente definidos na comunidade, logo se tornando nominadores, pais e com capacidade de participar da vida política da aldeia.

Nesse sentido específico, acrescentaria um item, presente em quase todas as análises sobre os batoques auriculares jê. Os Xavante (como os Canela, Mebengokre, Krahó e Xikrin, por exemplo) mudam seus batoques ao longo da vida, sendo os pequenos e finos pedaços de embira pintados de urucum quando da iniciação progressivamente substituídos por grossos cilindros quando mais velhos. Isso significa, segundo os autores que analisaram a questão, um aumento na capacidade de aprender-ouvir-conhecer.

Voltarei a esse ponto adiante, buscando retomar algumas de suas implicações quanto ao ponto de vista jê sobre o funcionamento do corpo. Contudo, é importante que o leitor perceba que essa função simbólica exercida pelo "ouvir", associada à compreensão do que é dito (e representada pela furação das orelhas, uso dos batoques auriculares e progressivo aumento em sua espessura), é uma regra, no que diz respeito aos Jê. 
No que diz respeito aos Canela, por exemplo, como nos escrevem Crocker e Crocker (2009), parece ocorrer o mesmo que junto aos Kayapó. Segundo ele, a furação de orelhas simbolizaria e tornaria aptos ao amadurecimento os meninos. Para os Canela, os jovens com orelhas perfuradas são mais receptivos aos conhecimentos a eles passados pelos mais velhos, sendo o ato de aconselhar traduzido pelos Canela como hapak khre, ou seja, "abrir os ouvidos do outro". Anthony Seeger (1980, p. 46-47), ao tratar dos Suyá, escreve sobre a correlação entre saber-ouvir-compreender e seu papel na integração social do sujeito:

Uma pessoa que é completamente integrada socialmente "ouve, compreende e sabe" claramente. Uma pessoa que ouve e compreende mal, também age mal. [...] Na realidade, acredita-se que o ouvido seja o receptor e o depositário de códigos sociais, ao invés da "mente" ou do "cérebro".

O mesmo parece se dar com relação aos Xikrin, conforme o relato de Cohn (2000, p. 200):

Para os Xikrin, saber, conhecer, aprender, entender e compreender estão todos inseridos em duas capacidades, a de ver e ouvir. Quando afirma saber ou ter aprendido algo, um Xikrin pode optar entre dizer arym ba kuma, o que poderíamos traduzir como "eu já ouvi”, e arym ba omunh, que poderia ser traduzido por "eu já vi”. Quando, correspondentemente, se refere a ter ensinado algo a alguém, dirá ba kum akre (eu mostrei a ele/a) ou ba kum iaren (eu contei a ele/a). Do mesmo modo, a capacidade de aprender e entender é correlacionada às capacidades sensoriais de ver e ouvir, e as crianças devem desenvolver esses órgãos.

No entanto, não concordo plenamente com a autora em determinado ponto: segundo penso, não se trata de relacionar as capacidades sensoriais ao desenvolvimento daqueles órgãos, mas de buscar focar em seus aspectos simbólicos: o ouvido per se não é o responsável pela audição, tampouco a cabeça pela compreensão: faz-se necessário percebê-los enquanto processos, ou a partir de aspectos ligados à (e não necessariamente focados na) corporalidade ameríndia. Quando da furação de orelhas, os Xavante não estão intervindo no corpo, mas sim nas capacidades sensoriais por meio do corpo: o batoque no lóbulo inferior não é a finalidade última do ritual, mas uma forma de simbo- 
lizar processos ligados à compreensão e entendimento do mundo pelos quais aquele indivíduo passou.

Mais que isso, a orelha perfurada liga os Xavante no ritual de iniciação com os demais membros de seu grupo. Pode-se dizer que ele nasça, socialmente falando, posto que aquele indivíduo responsável pela perfuração de suas orelhas tenha que passar por restrições alimentares e sexuais bastante parecidas com aquelas observadas na couvade, como veremos mais à frente. Há, ainda, outro elemento fundamental para a boa compreensão desse tipo de relação entre os Xavante, o que se denominará aqui como "relações de substância", algo já bastante discutido por antropólogos estudiosos dos Jê e possivelmente já gasto, mas sobre o qual muito pouco se discutiu, no que diz respeito aos Xavante.

Ora, vimos que os Xavante definem a concepção a partir da manutenção de coitos contínuos - afinal, como em outros Jê, o corpo da criança se forma pelo acúmulo de sêmen, sendo seu suprimento uma condição essencial para a boa formação do corpo do feto, podendo a família inclusive recorrer a parentes do esposo, se necessário, como também vimos. Tal tipo de relação, e aquelas que lhes são tributárias, passaram a ser conhecidas na etnologia brasileira como "relações de substância". Apesar de haver sido utilizada, enquanto conceito, tanto por Melatti (1978) quanto por DaMatta (1970), o antropólogo que parece ter melhor explorado essa noção é Anthony Seeger (1980, p. 129):

Os Suyá acreditam que uma criança é criada pela acumulação gradual de sêmen no útero de uma mulher. Apenas o homem contribui para o crescimento do feto, acrescentando mais sêmen por meio de repetidas relações [o mesmo ocorre com relação aos Xavante, como anteriormente visto]. A mulher fornece apenas o recipiente. Sua contribuição física se dá por meio da alimentação depois do nascimento da criança. Um homem esfregou seu corpo e disse "é tudo sêmen", enfatizando que seu corpo tinha sido criado por seu pai. Pais, filhos e siblings plenos estão ligados para toda a vida por laços de identidade corporal. Não se acredita que maridos e mulheres tenham os mesmos corpos: eles são diferentes, feitos de diferentes sêmens e alimentados por diferentes mães. No entanto, para os siblings e seus pais, quando alguma coisa acontece a um de seus corpos, os outros podem ser afetados, especialmente quando os outros são fracos ou doentes. Por exemplo, quando alguém tem um pé infeccionado - inchado e ardendo com a infecção - o pai, a mãe, os irmãos e irmãs plenos, além de seus filhos, evitarão comer pimenta, sal, a carne avermelhada de determinado peixe, ou peixe com dentes afiados. [...] Esses mesmos parentes tomarão cuidado para 
não se cansar demasiado pela mesma razão. Essa crença está na base de muitas restrições e de atividades: você lhes obedece não por si mesmo, mas por um parente próximo.

Nos Xavante, o mesmo parece se dar (até porque, de igual forma que os Suyá, para eles o homem é o único responsável pela formação do feto), como veremos a seguir:

À medida que a época do nascimento se aproxima, o futuro pai deve observar uma série de restrições. Ele não deve matar um tatu pois isso impediria a criança de vir à luz; tampouco deverá matar um tatu grande, pois isto causaria um parto longo e doloroso à sua esposa. Ele deverá também evitar de caçar jibóias, seriemas, araras e certas espécies de peixes, principalmente o barbado e o cachorro. [...] A futura mãe, por outro lado, não é alvo de quaisquer restrições e geralmente consegue levar suas atividades cotidianas até dois ou três dias antes do parto. (Maybury-Lewis, 1984, p. 109).

Note-se, entretanto, que algumas das restrições, ao contrário do que afirma Maybury-Lewis (1984), se aplicam, sim, às mulheres: estariam proibidos o mutum (caso a mulher o coma, o bebê "vai demorar a chorar" e morrerá dentro da barriga); o tatu (a restrição se aplica ao casal: caso venham a tocar, matar ou comê-lo, "especialmente a cabeça", o bebê ficaria com diarreia com sangue; podendo ainda encurtar em tamanho ou, ao engatinhar, a criança comeria terra); ema (alimento interditado aos pais, a fim de "não afetar o espírito da criança"); tripa de jabuti (se os pais tocarem, caçarem ou comerem podem ter problema com vômito e acidez no estômago do bebê); caititu (apesar de ser permitido ao pai caçá-lo, é proibido tanto a ele quanto à mãe comer ou tocar sua carne, sob pena do corpo da criança encurtar); carne de arara (da mesma forma, pode ser caçada pelo pai, mas não comida na gestação: "mesmo que o bebê nasça grande, se os pais tiverem comido arara o bebê emagrecerá rapidamente por causa das penas").

Quanto ao parto, em si, entre outros povos jê, diversos autores tratam do assunto: Lux Vidal (1977, p. 88) faz uma bela descrição do parto entre os Xikrin, acompanhado por ela em 1972:

Acompanhada de sua mãe, a jovem mulher fora para o mato a fim de dar à luz [nota da autora: “As mulheres não dão à luz dentro das casas e os homens nunca 
assistem a um nascimento"]. Disseram-me que a avó, depois de ter massageado durante algum tempo o cordão umbilical em direção ao recém nascido e depois de ter limpo sumariamente a cabeça, cortou o cordão umbilical que nunca é amarrado. A placenta é enterrada e costuma-se envolver o ventre da jovem mãe com faixas de Envira, como se faz em caso de doença ou de dores. Em seguida, as mulheres voltam para casa.

A mãe instalou-se sobre uma esteira e espalmou o rosto e corpo com urucu. A avó também passou urucu no recém-nascido e, com a palma da mão esquentada sobre o fogo, massageava constantemente a testa e o ocipício da criança. A cabeça foi submetida a uma verdadeira modelagem e as parentes, da categoria kwatui (MM, FM, FZ), se revezavam na operação [nota da autora: "De acordo com as informações de um médico presente na ocasião, estas massagens ( $k r a \tilde{-}$ iadjoro) reduziriam o edema pós-parto, que, entretanto, se faria naturalmente. As índias apenas aceleram o processo. É claro que aqui o costume está ligado a um contexto de relações sociais, associado também a uma preocupação de ordem estética.'].

Também Vanessa Lea (1999 apud Rocha, 2001, f. 30) argumenta que, entre os Kayapó, logo após o nascimento, um bebê começa a ser moldado nas mãos das mulheres (crânio, pernas e braços). O mesmo ocorre, conforme pude observar, entre os Xavante. Segundo afirmam, a massagem onde se molda, literalmente, o crânio do bebê (e o banho dado na criança após o nascimento) são essenciais para sua formação enquanto ser humano. A explicação que recebi, tanto de homens quanto de mulheres sobre esta prática, não tem fundo estético: é um ato moral.

Nesse sentido, como aponta Turner (1995, p. 158), a cabeça é a extremidade mais importante do corpo, onde se localizam os sentidos e o discernimento: é o locus público por excelência, de modo que a massagem na cabeça da criança reforça, simbolicamente, o primeiro passo na construção daquele ser enquanto pessoa social - contudo o recém-nascido ainda não pode ser considerado "pessoa", como veremos mais à frente. As técnicas pós-parto irão tratar de separar, gradualmente, a substância daquela criança da de seus pais.

A noção de substância aqui é tão importante que, quando um Xavante viaja, é comum pedir a um parente próximo - irmão ou "primo", isto é, membro de seu clã, conforme escrevem Giaccaria e Heide (1984) em trecho citado anteriormente -, que mantenha relações sexuais com sua esposa. Aos (poucos) que admitem tal prática, a razão é clara: são todos "iguais", ou seja, feitos da 
mesma substância, de modo que não interferirão no desenvolvimento do feto diferentes sêmens, por não ser esse o caso: mesma substância gera mesma substância. O que importará, ao longo da vida da criança, não é tanto quem lhe forneceu o sêmen, mas principalmente quem exercerá o papel de pai ao longo de sua vida - mesmo porque, entre os Xavante, em certos rituais, nesse papel ele será substituído ritualmente pelo irmão da esposa.

Entre os Xavante, da mesma forma que entre os Kayapó, como vimos acima, a parturiente é assistida pelas mulheres mais idosas, sem participação dos homens - em especial o pai (Maybury-Lewis, 1984, p. 110). Continua o autor:

Durante alguns dias imediatamente após o nascimento (em dois casos reais, foram cinco), o marido deve viver calmamente dentro e nas proximidades de sua casa. Pode ocupar-se com a feitura de armas ou de qualquer outra coisa em que ele esteja trabalhando manualmente no momento mas não deve sair para caçar ou pescar e não pode comer carne. Os Xavante enfatizam que ele deve moderar suas atividades durante este período: ele deve comer e beber pouco; não pode participar das reuniões do conselho dos homens nem envolver-se em discussões ou brigas; deve abster-se de intercurso sexual com mulher alguma; deve, enfim, viver uma vida tranqüila. (Maybury-Lewis (1984, p. 110).

Mencionei anteriormente algumas restrições que se passam durante a furação de orelhas, tanto por parte do iniciando quanto daquele que executa a tarefa de lhe perfurar as orelhas. Além das restrições alimentares (que atualmente incluem álcool, comidas gordurosas, azeite, sal e café), certamente prefiguram as sexuais. Uma das explicações que tive para isso foi o fato de que "no sexo a mulher toma muita energia do homem". Como apontam alguns autores (Coelho de Souza, 2002, Crocker; Crocker, 2009; Rocha, 2001; Vidal, 1977, dentre outros) as restrições de ordem sexual são comuns em muitos povos jê.

A título de hipótese, sugiro aqui que, como os corpos do pai e do filho recém-nascido ainda não estejam completamente separados, o gasto da substância que gerou o corpo do bebê repercutiria em sua própria saúde, o que também explica o porquê de tanto Maybury-Lewis (1984) quanto Giaccaria e Heide (1984) serem tão taxativos ao afirmarem que não há, dentre os Xavante, a prática de masturbação entre os homens: seria um desperdício de seu próprio princípio vital. 
Quanto a restrições alimentares, uma das explicações propostas por Seeger (1980, p. 129) é a de que comer alimentos vermelhos (cor de fogo) ou peixes com dentes pontiagudos traria como efeitos calor e pungência, respectivamente. Penso que essa explicação seja incompleta, pois não abrange os mecanismos pelos quais tais efeitos operam. As crianças são mais suscetíveis, como veremos a seguir, por terem o corpo ainda "mole", não terem ainda um nome e não serem ainda pessoas. Seu corpo está literalmente "aberto" a esse tipo de influências externas, como a lista de alimentos restritos no pós-parto nos permite perceber. Uma prova disso é que o meio mágico mais utilizado para salvaguardar a saúde das crianças pequenas é o uso dos dañipsi: pequenos cordões feitos com propriedades mágicas colocadas no pescoço, punhos e tornozelos dos pequeninos. Ora, o pescoço conecta a cabeça ao tronco e é análogo, do ponto de vista funcional, aos braços e cotovelos que conectam mãos e pés: justamente as partes com maior significado social. Trata-se, penso, de uma tentativa simbólica e mimética de demarcar os limites do humano, posto que o recém-nascido ainda não possui um nome - o que lhe conferiria humanidade. Caso contrário, como veremos a seguir, o corpo recém-nascido (mas ainda não desenvolvido, autônomo e "fechado" por um nome, que the confira existência social) corre o risco de adquirir propriedades indesejadas (isto é, não humanas).

São restritos os seguintes alimentos: pacu (faz o corpo da criança arredondar-se); mandi (causa fraqueza e emagrecimento na criança); cará branco (o bebê fica sem cabelo); coco de buriti (arredonda o corpo); pequi (acidez no estomago, na boca e atrapalha o sono); partes da anta (o bucho da anta fere a cabeça da criança e faz cair seu cabelo; a tripa dá diarreia e fraqueza; já comer o olho da anta fará com que a criança tenha olhos bonitos, "bem puxadinho, igual ao da anta"); abelha (dá chiadeira no nenê); bucho de cervo (o bebê fica estufado); quati (emagrecimento e desnutrição); seriema (emagrecimento); milho (comer o milho riscado irá "escurecer a pele" do nenê); feijão (a pele da criança fica preta); e piau (prejudica a vista do bebê e entope o nariz). Também Giaccaria e Heide (1984, p. 138-139) trazem uma lista dos alimentos restritos ao casal no pós-parto: tamanduá e tamanduá-mirim (compromete o crescimento da criança), raposa (causa emagrecimento); paca (a criança não dormirá), piranha (sua pele ficará preta), cumbaru (causaria calvície na criança), dentre outros (a maioria já mencionada aqui). 
Confirmando o que foi dito acima, escreve Maybury-Lewis (1984, p. 111112) que os Xavante manifestam a crença (comum entre os Jê) de que

uma criança seja macia, "mole" (wadi $\left.{ }^{2}\right)$ desde a época anterior ao seu nascimento até alguns dias depois do parto. Por ser o nenê especialmente vulnerável neste período o pai precisa tomar precauções especiais para não lhe causar mal. As atividades de sua mãe não são vitais para sua saúde na mesma proporção que as do pai. [...] Os Xerente, que já eram bastante aculturados quando os estudei pela primeira vez, afirmavam igualmente que um laço une pai e filho ao longo de suas vidas. Assim, quando uma criança adoecia, eles buscavam a causa da doença nos excessos (frequentemente alcoólicos) cometidos pelo pai. Um homem que se embriagava tendo o filho doente era, subsequentemente, considerado seu assassino caso a criança viesse a falecer. Não consegui descobrir se os Xavante acreditavam que as atividades do pai influíam em seu filho durante toda a vida ou apenas na crise do nascimento. A relação é, no entanto, inequivocadamente assimétrica: um filho não prejudica a saúde de seu pai.

De fato, o recém-nascido é visto, entre os Xavante, como um ser bastante frágil - como mencionado, aquele pequeno ser ainda não possui uma condição humana, estado este atingido apenas após seu corpo estar duro o suficiente para suportar carregar um nome: como escreve Lopes da Silva (1980, f. 39), o nome masculino é uma expressão de conquistas ou aumento de força vital. A autora demonstra como os nomes se associam às categorias de idade, ligadas às fases de desenvolvimento do indivíduo.

Como vimos, a criança xavante, tão logo nasce, é frágil demais para suportar um nome: "O nome é uma carga pesada demais para seu corpo frágil, ‘mole' que acabará adoecendo, até morrer." (Lopes da Silva, 1980, f. 39). Como observa a autora, um nome dado a um recém-nascido permitiria que a doença entrasse em seu corpo, sendo necessário que se espere um pouco até que seu corpo cresça e endureça um pouco, tornando-se mais resistente segundo Lopes da Silva (1980), tais regras se aplicariam também aos nomes em português, regra que ainda é seguida pelos Xavante com quem conversei a respeito.

Nos registros de nascimento nas aldeias, é comum a menção às crianças como "RN de Fulana", ou seja, recém-nascido(a), filho(a) de fulana.

2 Uwa di, literalmente "estar mole".

Horizontes Antropológicos, Porto Alegre, ano 16, n. 34, p. 453-477, jul./dez. 2010 
Conversando com alguns índios, percebi que o nome em português também deveria ser sonhado, ou "dado" em homenagem a alguém, que se tornaria o padrinho waradzu daquela criança. Seja como for, a criança xavante, do sexo masculino, ${ }^{3}$ receberá seu nome a partir dos oito ou dez meses de idade, segundo Lopes da Silva. No entanto, como salienta a autora, isto não se prefigura regra - podendo um menino receber seu nome quando tem dois ou três anos de idade, ou simplesmente não receber nome algum enquanto ainda for muito pequeno.

Tal fato reforça a tese de que ter um nome é o reconhecimento da personitude de seu portador, situando-o no quadro de relações que o definirá socialmente ao longo de sua vida. Como a autora mesmo salienta, a maior parte dos Xavante se esquece de seu nome enquanto watebremi (crianças pequenas), seja seu próprio nome, de seus filhos ou de um parente próximo (Lopes da Silva, 1980, f. 40). As crianças são simplesmente chamadas por babati ou tsaré (ambas as palavras significam a mesma coisa, "caçula").

Interessante perceber que, diferentemente de outros Jê, os Xavante não possuem o hábito de pintar as crianças pequenas - refiro-me especificamente aos Xikrin, que pintam regularmente seus filhos pequenos (Vidal, 1977, p. 9293). A mesma autora, mais tarde, escreverá que "pintar o bebê é uma manifestação de carinho e interesse da mãe pelo filho e faz parte do processo de socialização das crianças. As mães Kayapó passam horas a fio pintando seus filhos." (Vidal, 2000, p. 146). Como Coelho de Souza (2002, f. 576) observa, a pintura "torna o recém-nascido belo e contribui para fazer dele um ser humano"; nos mitos, por exemplo, seria pela pintura que os personagens não humanos se transformariam em humanos (a partir do material jê setentrional analisado pela autora). Entretanto, em se tratando da criança xavante, não penso que a pintura seja tão palco de relações sociais quanto o é, no que diz respeito aos Jê do norte.

Como já mencionado aqui, as cordas de fibra vegetal amarradas nos pulsos, tornozelos e pescoço são os únicos adornos corporais visíveis em crianças pequenas. O nome, por outro lado, parece conferir laços sociais mais sólidos - tais laços e conjuntos de atitudes esperadas dos meninos, enquanto pequenos

3 A nominação feminina passa por outras vias, como veremos mais à frente. 
Xavante, somente aparecerão quando forem mais velhos, por ocasião do ritual do oi'ó (entre 6 e 10 anos, aproximadamente).

Voltando à nominação das crianças xavante, como explica Lopes da Silva (1980, f. 41, grifo da autora):

Um nome novo dado a um menino pequeno é necessariamente captado durante o sonho, por parentes próximos a Ego, de sua mesma linha de descendência ou por tios maternos próximos que freqüentemente "sonham" nomes para seus sobrinhos. Algumas pessoas "vêem" o nome durante o sonho e outras o "ouvem". Também as canções que os homens maduros ensinam aos meninos que moram no hö (casa dos solteiros) e que são cantadas no meio da noite, de casa em casa, são "sonhadas" [...] Em relação a este "sonhar" outro dado que me foi possível colher é que é uma atividade essencialmente masculina: as mulheres "não sabem pensar", têm a cabeça "dura", dizem os homens Xavante. De fato, de todos os nomes sonhados para os watebremi e ba'ono (meninas) da aldeia do Paraíso, só 6 foram sonhados por mulheres.

A autora acrescenta, ainda, que na nomeação dos watebremi há a preferência por nomes de avôs paternos (qualquer homem da segunda geração ascendente); seguidos por nomes "novos" (inéditos, sonhados por um homem da linhagem de ego da geração ascendente); e nomes dados pelo irmão da mãe (contudo, será mais comum este nominar o filho da irmã na ocasião do rito de iniciação xavante, quando da furação de orelhas). O primeiro nome do menino xavante viria acompanhado de uma cerimônia realizada pelo irmão de sua mãe, quando a criança tem entre 5 e 6 anos de idade. Tal cerimônia, contudo, não foi acompanhada nem por Maybury-Lewis (1984, p. 296), nem por Lopes da Silva (1980, f. 43), tampouco sendo mencionada por Giaccaria e Heide (1984, p. 249).

E no caso dos nomes femininos? Lopes da Silva (1980, f. 84) diz a esse respeito que no caso das meninas

não há cerimônia de nominação a não ser quando já são adultas. Até então, algumas ficam sem nome, mas a maioria recebe um "nome de menina", o ba'ôtõre ñi tsi. Ele também é designado como ipredu'ore ñi tsi (literalmente, nome de "antes de ser grande, madura"). Apesar de a palavra Xavante usada aqui ser a mesma que designa os nomes masculinos e os nomes das mulheres adultas ( $\tilde{n} i$ ts $i=$ nomes), os ba'ôtõre ñi tsi dizem respeito a características físicas ou do temperamento da criança, ou relembram circunstâncias que viveu ou acontecimentos 
que marcaram sua vida, diferenciando-se, assim, dos nomes de adultos ligados a outros critérios de classificação [...]. Os "nomes de menina" não são usados com freqüência e geralmente não são conhecidos a não ser por aqueles que vivem em contato mais estreito com a criança, notadamente os que fazem parte do seu grupo doméstico. Os nomes de menina fazem parte, realmente, da esfera doméstica. Atualmente, é o nome em português o mais usado como vocativo pelas crianças entre si. Os adolescentes e adultos se dirigem a elas tanto pelos nomes pessoais em português quanto por termos de parentesco, havendo uma ligeira preponderância do uso dos nomes em português.

Interessante, contudo, é o que se segue. Segundo Lopes da Silva (1980), o "nome de menina" - apesar de não ser o nome, propriamente dito, da mulher - virá a ser carregado de tabu e interdições. Maybury-Lewis (1984, p. 299) nos dá uma pista nesse sentido, ainda que sem perceber, ao afirmar que algumas mulheres, ao serem perguntadas, "insistiam em dizer que não tinham nomes, apesar das repreensões exasperadas de seus maridos, que lhes diziam para deixarem de ser tão tolas". Tal informação, no entanto, não condiz com o que afirma Lopes da Silva (1980), segundo quem pronunciar o "nome de menina" de uma adulta seria evocar seu tempo de solteira (as Xavante se casam muito novas), tempo em que não tinha ainda seu nome verdadeiro e não era considerada ainda madura, sem marido ou filiação a um grupo cerimonial - como diz a própria autora, sem um nome "personalizante", desfrutando de seu lugar na sociedade.

Se o nome de menina é evitado, por evocar essa fase despersonalizada mas descritiva, o nome de menino é esquecido por ser desnecessário. Como observa Lopes da Silva (1980, f. 114) mais à frente, em seu texto,

se o homem é importante publicamente para os Xavante, o sistema de nominação masculina ressalta aspectos domésticos e o nome é transmitido em cerimônia privada, se a mulher importa no âmbito doméstico, sua nominação coloca em relevo sua pertença à sociedade como um todo, através de um ritual coletivo, público, extra-doméstico.

Esse ritual, público, pode ser visto como um rito de passagem de ingresso daquela menina na sociedade, sendo a "vergonha" de se pronunciar seu "nome de menina" uma evitação formal de se evocar um tempo em que ela ainda não pertencia, nos termos usados pela autora, "à sociedade como um todo". 
Coelho de Souza $(2002$, f. 568, 571) virá a sintetizar o sistema de nominação, no que tange ao gênero, da seguinte forma: de um lado, os nomes femininos (ligados à natureza, referindo-se a nomes de animais e/ou plantas); de outro, os nomes masculinos, ligados aos antepassados (adquiridos pelo contato com o sobrenatural). Na verdade, os escritos de Lopes da Silva (1980, 1989) parecem apontar ainda outro caminho, mais promissor.

Para Lopes da Silva (1989, p. 337), a significância social dos nomes xavante residiria em três aspectos: 1) seriam meios de estabelecer relações interpessoais; 2) nomes são elementos constitutivos de si (self); e 3) acima de sua relevância social ou pessoal, os nomes xavante possuem importância ontológica, relacionando o mundo natural ao sobrenatural:

Personal names are a necessary element of the Xavante definition of human nature, as only persons have the capacity of participating in the process of creation and remodeling of the world's dimensions: the past, the present, the social, the natural, and the supernatural.

No que diz respeito à nominação feminina, a questão aqui é: por que o nome opera, no que tange à origem, de forma tão diversa da masculina?

Sem entrar no fulcro da questão, e seguindo as pistas dadas por Lopes da Silva em seus trabalhos, arrisco afirmar, a titulo de hipótese, que a ligação do ritual de nomeação feminina xavante com o milho ${ }^{4}$ e a menção de certos animais bastante presentes na mitologia e nos ritos xavante (macaco, periquito, peixe, etc.) têm a função de apresentar de forma ritualizada determinados tipos de relações do mundo animal com/e da sociedade humana. Além disso, da mesma forma que ocorre com os wapté em sua cosmologia, penso que a nominação feminina, da forma como aconteça, tenha o papel de salientar o papel criador da mulher.

Em sua análise sobre o mito timbira de Auké, DaMatta (1970, p. 94) escreve que

a categoria mulher parece ficar situada numa área onde é possível a sua conexão com o plano da natureza. A categoria mulher, portanto, estaria situada entre homens e animais, donde sua ambigüidade, isto é, sua capacidade de, em certas

\footnotetext{
4 Há entre os Jê o mito de que o milho teria sido dado aos índios (a uma mulher) por periquitos.
} 
circunstâncias, organizar ou desorganizar relações sociais. Quando o potencial reprodutivo da mulher acarreta um beneficio para a sociedade, como ocorre quando sua gravidez é normal, ela organiza relações sociais. Mas como o potencial reprodutivo da mulher é algo que o grupo não controla, pois é dirigido por processos naturais, existe sempre a possibilidade da mulher desorganizar relações sociais e colocar em perigo a vida de sua comunidade [...]. Em outras palavras, pode-se dizer que a mulher pode servir como um elemento destrutivo e construtivo.

Um bom exemplo do que escreve DaMatta acima é o mito xavante da origem do milho: os Xavante comiam "pau podre" antes de descobrirem o fogo - uma variante xavante do mito lévi-straussiano do desaninhador de aves, imortalizado em seu $O$ cru e o cozido (Lévi-Strauss, 2004) - e de uma mulher receber, dos periquitos, o milho. Como Maybury-Lewis (1984, p. 351) aponta, são histórias que tratam da passagem do estado de natureza para o estado de cultura.

Para Lévi-Strauss (2004, p. 202) esses mitos oporiam "o estado de natureza ao estado de cultura, e até mesmo ao estado de sociedade: quase todas as versões [dos mitos jê sobre fogo e milho] fazem remontar à conquista do milho a diferenciação dos povos, das línguas e dos costumes". Explica o autor:

No estado de natureza, os humanos - terrestres - praticam a caça mas ignoram a agricultura; alimentam-se de carne, crua segundo várias versões, e de podridão vegetal: madeira em decomposição e cogumelos. Ao contrário, os deuses - celestes - são vegetarianos, mas seu milho não é cultivado; ele cresce espontaneamente e em quantidade ilimitada numa árvore da floresta, cuja essência é especialmente dura (ao passo que o milho cultivado tem caules finos e quebradiços). Esse milho é, portanto, na ordem dos alimentos substanciais, simétrico à carne, alimento substancial dos homens em estado de natureza. (Lévi-Strauss, 2004, p. 202).

Se a mulher possui esse papel de mediadora entre os diferentes planos do pensamento xavante, não causa estranheza afirmarmos, pois, que o sistema de nominação feminina reflita tal papel. Nesse sentido, o nome sintetiza um dos princípios básicos da cosmologia xavante: as coisas são criadas ao serem nominadas. Penso que a capacidade de criação seja um dos princípios fundamentais da cosmologia jê e que seu sistema de nominação reflita isso: nominar é reconhecer a existência, enquanto se põe ordem e se classifica algo. 
Como Coelho de Souza (2002, f. 581-582) indica, haveria um duplo aspecto na onomástica jê:

Nomear, dizíamos, é objetificar: isso corresponderia ao aspecto "corpo" do nome, ao nome como constituinte da pessoa, à sua face "interna". Em sua face "externa", que remete ao exterior e ao sobrenatural, faz do portador um protagonista mítico, um personagem ritual, um animal. Minha sugestão é que isso, como a vestimenta cerimonial, é parte do que cria a diferença de pontos de vista necessária à ativação da pessoa como sujeito.

Para a autora, tal relação teria algo em comum com a amizade formal, ${ }^{5}$ na qual

o amigo formal seria o que contradiz, nega, evita e inverte seu parceiro, e que lhe abre, assim, um campo pessoal, não sem dúvida, como agente dotado de razão, vontade e liberdade [...] mas como ser de certa maneira único, diferenciado e, sobretudo, provido de uma dinâmica própria, em suma, como sujeito. (Carneiro da Cunha, 1978, p. 61).

Contudo, como bem demonstra Lopes da Silva (1980, f. 210-11), dialogando justamente com Carneiro da Cunha,

o "outro" não é somente o amigo formal, mas também o nominador, o membro de uma categoria ou classe de idade de metade oposta, o afim que se evita. O "outro", evita-se, mantém-se à distância, controla-se-lhe os contatos, formalizando-os, regrado-os com precisão; mas ao "outro" também se incorpora, igualando-se a ele num sistema de posições cerimoniais, tornando-se o próprio "outro" ao usar seu nome e, ao substituí-lo no tempo, garantir a continuidade de sua existência e, por extensão, a de toda a sociedade. Para com o "outro", portanto, duas atitudes, expressão de dois caminhos conceituais para a sua apreensão, para a sua captura: a evitação, a distância, a separação ostensiva, declarada, para a qual se mantém a sociedade atenta e consciente da diferença: a amizade formalizada; ou, por outro lado, a negação da diferença e a incorporação do "eu" ao "outro": a identidade na nominação.

Para os povos jê setentrionais, após estudos feitos na década de 1970, é comum a alusão a dois tipos de relações formais: a amizade formal, que implica evitação entre indivíduos; e o companheirismo formal, relação oposta, implicando solidariedade mútua. Tal modelo, contudo, é diferente no que diz respeito aos Xavante, como mostra Lopes da Silva (1980, f. 212 e seguintes, principalmente). 
Sendo assim, talvez fosse interessante acrescentarmos um outro aspecto aos já mencionados por Coelho de Souza (2002) (fabricação e metamorfose): o da incorporação. Veremos mais à frente que um dos pressupostos da cosmologia jê é o de que elementos externos possam ser incorporados por meio da captura. De certa forma, o estupro ritual das mulheres no wai' $a$ ou o coito que as mulheres mantêm no decorrer do ritual de nominação com membros das categorias de idade correspondentes funcionam como ritual de incorporação de elementos internos (as mulheres) à sociedade (por meio da introdução delas no ritual ou de sua nominação). Isso nos leva a uma questão-chave.

Vimos que, pela noção de substância, bem como pela construção da pessoa entre os Xavante, os mais jovens são os que estão mais suscetíveis ao desenvolvimento de doenças causadas por "algo de fora", por diversas razões, discutidas acima. Do mesmo modo, ao longo de meu trabalho de campo, sobre a origem de doenças causadas por lombrigas, vírus e bactérias entre os Xavante, meus informantes são quase unânimes ao afirmar que os pais as transmitem aos filhos após contraí-las, consumindo alimentos e bebidas "de fora" (refrigerante, café, cerveja, açúcar, azeite, etc.).

Contudo, não parece uma coincidência o paralelo óbvio que pode ser traçado entre as comidas interditas aos pais no período de resguardo e aquelas apontadas pelos entrevistados enquanto causadoras de vírus, bactérias, etc. O que se tem, aqui, não é nem uma visão waradzu (ou seja, não indígena) dos vírus e bactérias; o que se preconiza são bactérias que vêm pelo azeite e pelo refrigerante. Tampouco poderíamos falar de uma "releitura xavante" sobre bactérias e vírus, posto que tais elementos, a priori, não existem no universo cosmológico xavante. O que temos, proponho, é uma forma inteiramente original de se pensar a doença em relação às ideias acima e a partir do que os Xavante apre[e]ndem por meio das ações de educação em saúde levadas a cabo pela Fundação Nacional de Saúde (Funasa), em área. Como explicar isso, afinal?

Uma possível explicação poderia ser a da perda cultural. Nesse sentido, poderíamos afirmar que os Xavante sentiram os efeitos do contato interétnico e buscaram, em sua cosmologia, dar conta desses efeitos, buscando explicar, à sua maneira, que alimentos como refrigerantes e álcool fazem mal. Entretanto, a desvantagem desse tipo de explicação seria não levar em conta a dinâmica 
mesma da cosmologia xavante. Proponho, neste artigo, a noção de cultura não como resultante de processos de assimilação, mas conduzindo, ela própria, processos de reflexão sobre o Outro. Penso que os depoimentos dos Xavante sobre as suas doenças nos sejam mais úteis se forem tomados e trabalhados como uma reflexão mítica sobre a experiência histórica (afinal, os vírus e bactérias surgem quando do contato com o waradzu).

Os Xavante possuem uma historicidade específica por meio da qual eventos históricos podem ser transformados, ainda que sejam considerados como "passado", aos moldes da historiografia ocidental: as expressões da metafísica xavante, tais como suas musicalidades, oralidades, territorialidades e mesmo suas identidades - conforme indica Lopes da Silva (1984) - estão em permanente devir e, por isso mesmo, devem permanecer no plural. Parece interessante trazer um exemplo, mencionado pela autora:

Ouvi waradzu bo pá watsu'u (“a história do Waradzu bo pá”) pela primeira vez, narrada por Tsimih'oropupu, em São Marcos, em 1972. Ouvi outras versões mais tarde, em outras aldeias. Relata, essencialmente, a experiência de uma jovem Xavante que vai à mata em busca de mel. Lá, encontra-se inesperadamente com um homem branco, cuja peculiaridade era o tamanho de seu pênis: "tão comprido que carregava apoiado nas costas" ( $w a r a d z u=$ branco, "civilizado", não-índio, estranho; $b o=$ pênis; $p a ́$ = comprido; watsu' $u=$ estória-história). Os dois acabam por ter uma relação sexual em conseqüência da qual (dado o tamanho do pênis) a moça morre. Preocupado com a demora da filha, o pai vai à sua procura e, finalmente, a encontra. Vendo o que lhe acontecera, sai em perseguição ao estranho, disposto a matá-lo a golpes de borduna. Encontra-o, atinge-o na nuca mas não consegue matá-lo. Descobre, afinal, que "sua cabeça era na perna, embaixo do osso do joelho", e não acima da nuca, como no caso dos homens Xavante. Atinge-o nessa "cabeça" e, finalmente, consegue matá-lo.

Não pretendo apresentar aqui uma análise detida (e merecida!) desse mito a partir de sua formulação original, em Xavante. Resumi suas idéias centrais para, simplesmente, indicar algumas das noções que sugere. Da perspectiva das preocupações deste trabalho, vejo neste mito um alerta para: a) a incrível capacidade reprodutora dos brancos, numa indicação de sua superioridade demográfica em relação aos Xavante; b) sua capacidade de destruição dos índios; c) sua estranheza ou monstruosidade; d) a dificuldade de serem vencidos pelos índios, que desconhecem seus pontos vulneráveis e não sabem como combatêlos; e) a necessidade que têm os Xavante de estudar os brancos e desenvolver modos eficazes de relacionamento para, afinal, enfrentá-los e vencê-los. (Lopes da Silva, 1984, p. 207). 
Penso que, à luz do que foi exposto até aqui, podemos ir um pouco além da análise de Lopes da Silva. Uma das mensagens das histórias xavante diz respeito à questão do que é ser humano: quando a ameba chega aos Xavante pela comida não indígena; quando a diarreia do branco mata, e a xavante, não; quando o branco é invencível, com sua cabeça no joelho; e tantas outras concepções do branco: em alguma medida, tais histórias nos falam algo sobre o que é ser Xavante em uma posição, relacional e perspectiva, com relação ao branco.

E é de propriedades corporais, em um contexto de relacionamento com o Outro, que trata a maior parte das histórias xavante: uma moça que se deitou com um lobo se tornou o gavião de cauda branca; o rapaz que comeu o clitóris da mãe se tornou branco; um jovem que ofendeu seu avô foi transformado em beija-flor; uma moça que traiu seu marido foi transformada em redemoinho, e seu amante, em jacaré; uma mãe e um filho que cometem incesto viraram antas... - tais histórias nos ensinam que as propriedades corporais mudam porque muda a condição humana: em tais episódios, os indivíduos se dessociabilizam.

Escreve Viveiros de Castro (2007, p. 323, grifo meu) a esse respeito que

Não é descabido definir o discurso mítico como consistindo principalmente em um registro do processo de atualização do presente estado de coisas a partir de uma condição pré-cosmológica virtual dotada de perfeita transparência - um "caosmos" onde as dimensões corporal e espiritual dos seres ainda não se ocultavam reciprocamente. Esse pré ou proto-cosmos, muito longe de exibir uma "indiferenciação" ou "identificação" originárias entre humanos e não-humanos, como se costuma caracterizá-lo, é percorrido por uma diferença infinita, ainda que (ou porque) interna a cada personagem ou agente, ao contrário das diferenças finitas e externas que constituem as espécies e as qualidades do mundo atual [...]. Donde o regime de "metamorfose", ou multiplicidade qualitativa, próprio

\footnotetext{
6 "Em Caosmose: Um novo paradigma estético, Félix Guattari desenvolve a noção de heterogênese: uma categoria relacionada à de causa eficiente, correspondente à constituição de universos de referência. Como colocado pelo autor, a heterogênese é 'uma dimensão de produção ontológica que implica que se abandone a idéia de que existiria um Ser subsumido às diferentes categorias heterogêneas de entes (...) Não existe uma substância ontológica única se perfilando com suas significações 'sempre já presentes' (...) Para além da criação semiológica de sentido, se coloca a questão da criação de textura ontológica heterogênea' (1992, p. 88-89). A heterogênese implica uma dinâmica de constante diferenciação, seguida por uma necessária singularização em novos territórios existenciais, que define os processos de desterritorialização e reterritorialização criativas." Sauma, 2007, p. 43, grifo meu).
} 
do mito: a questão de saber se o jaguar mítico, por exemplo, é um bloco de afetos humanos em figura de jaguar ou um bloco de afetos felinos em figura de humano é rigorosamente indecidivel, pois a metamorfose mítica é um acontecimento ou um devir (uma superposição intensiva de estados heterogêneos), não um processo de mudança (uma transposição extensiva de estados homogêneos). Mito não é história justamente porque metamorfose não é processo, "ainda" não é processo e "jamais foi" processo; a metamorfose é anterior e exterior ao processo do processo - ela é um devir.

Outro bom exemplo é trazido por Seeger (1980, p. 120), quando afirma que haja um "paralelo importante entre as ideologias de concepção e de herança em todas as sociedades jê": sociedades cuja ideia de concepção é centrada no pai/sêmen, a descendência é patrilinear; nas que pai (sêmen) e mãe (sangue) contribuem, o filho da irmã é o herdeiro para a chefia; e onde a teoria da concepção é mista, a forma de herança ideal também assim é. Para os Xavante, A'uwẽ quer dizer "gente", "pessoa"; enquanto os brancos são chamados de waradzu, termo tradicionalmente traduzido como "branco", "estrangeiro", "estranho". Partindo desses pressupostos, ser humano implicaria, necessariamente, ser Xavante. A problematização dessas categorias nos servirá como ponto de partida para algumas reflexões, a seguir. Por agora, parece interessante tentarmos recuperar o que foi dito até aqui.

Busquei demonstrar que, a partir das formas pelas quais opera o pensamento mítico xavante, elementos "de fora" (cerveja, refrigerante, bactérias, waradzu...) são apropriados de tal forma que passam a fazer parte de um regime específico de pensamento sobre o estatuto ontológico do Outro (no caso, nós). Penso que as ideias aqui desenvolvidas possam servir como complemento à explicação de fenômenos recentemente descritos por Ferreira (2009), Welch, Ferreira e Ventura Santos (2009) e Coimbra Jr. et al. (2002), dentre outros. Explicações a partir do convívio com os brancos, e/ou que levem em conta o sistema faccional xavante, também devem levar em conta um caráter de sua cosmologia voltada para a exterioridade, complementando-se entre si como sintetiza Carneiro da Cunha (2009, p. 361), em artigo recentemente publicado, "os [povos] amazônicos demonstram um extraordinário apetite pelo Outro e por suas bugingangas, chegando nisso a extremos canibais".

Não se trata apenas de afirmar que um dos problemas das ações de educação em saúde aqui observadas tenham se dado fora do contexto xamânico. 
Trata-se, também, de afirmar que o fato de serem externos também ao contexto ontológico xavante faça com que suas explicações cosmológicas, míticas e/ ou históricas se voltem para elas, abrangendo-as. Isso explica a superposição observada entre as explicações xavante sobre a ameba, ouvidas durante o trabalho de campo e trazidas aqui ao leitor, com as perspectivas xavante sobre a formação da pessoa (notadamente a partir das noções de substância). Chamo a atenção para o fato de que as comidas mencionadas pelos entrevistados (azeite, café, açúcar, etc.) serem tanto os alimentos que causam vírus e bactérias quanto aqueles interditos aos pais após o nascimento do bebê ou ao adolescente, após furar as orelhas. Não vejo isso como mera coincidência.

Uma primeira explicação nesse sentido poderia ser a de que isso se explica pela incorporação dessas comidas a uma sociedade xavante, devido ao seu convívio com o waradzu. Penso, todavia, que essa explicação não seja apenas insuficiente, mas errônea, por enfatizar os processos de desagregação cultural, desconsiderando a forma como os Xavante pensam a relação com os não índios. Dito de outra forma, segundo eles, não são os Xavante que são "assimilados" pela sociedade waradzu, são, ao contrário, os waradzu que são incluídos na cosmopráxis auwẽ.

Dois breves exemplos etnográficos do que foi dito. No wai'a (um dos mais importantes rituais xavante) observado por mim, na aldeia São José (Sangradouro), em 2000, chamou a atenção a substituição em diversos contextos da água bebida pelos participantes do ritual por refrigerante; e dos tradicionais bolos de milho por outros, comprados em padarias de Primavera do Leste. Da mesma forma, as cabaças nas quais os jovens iniciandos beberiam água foram substituídas por garrafas PET de refrigerantes. O outro exemplo foi observado na aldeia de São Marcos, em 2006. Na ocasião, conversando com um indígena, percebi que ele se revoltara com um dos cartazes colados na parede do posto de saúde, que mostrava uma conhecida atriz de televisão amamentando seu filho, recém-nascido. Dizia ele: "Os brancos tomam mamadeira e leite em pó! Por que eles querem que nós bebamos leite de peito? É só por que somos índios?! Também queremos ter direito a mamadeira e leite em pó!’ Após algum tempo, percebi que as latas de leite em pó que chegavam na aldeia circulavam pelas mesmas redes de troca "tradicionais" xavante, obedecendo àqueles circuitos de reciprocidade - Guilherme Faleiros, da USP, tem desenvolvido sua tese de doutoramento em antropologia a esse respeito. Que explicações poderíamos dar para esses dois exemplos? Os Xavante querem 
diminuir a desigualdade simbólica que os separa dos brancos? Eles têm sofrido uma irreparável perda cultural? Tais elementos (pães, refrigerantes, mamadeiras e latas de leite em pó) constituem "bens de prestígio" nas redes de reciprocidade das aldeias xavante, funcionando como elementos de disputa faccional e afirmação de poder? É possível.

Contudo, minha explicação é no sentido de afirmar que tais episódios (assim como a presença do azeite, sal e açúcar nas narrativas sobre o surgimento das amebas e vírus) demonstrem como os esquemas explicativos xavante se dão de modo a esclarecer suas próprias concepções históricas, cosmológicas, xamânicas e ontológicas. Trata-se de transformar o Outro em Eu, mais do que se transformar-se em Outro.

Proponho, assim, que a cosmologia xavante opere em relação a essa exterioridade, de modo a pô-la em perspectiva a partir de si, mais do que em oposição $a$ si.

\section{Referências}

BRITO VIANNA, F. F. de L. Boleiros do cerrado. São Paulo: Anna Blume, 2008.

CARNEIRO DA CUNHA, M. M. Os mortos e os outros: uma análise do sistema funerário e da noção de pessoa entre os indios krahó. São Paulo: Hucitec, 1978.

CARNEIRO DA CUNHA, M. M. "Cultura" e cultura: conhecimentos tradicionais e direitos intelectuais. In: CARNEIRO DA CUNHA, M. M. Cultura entre aspas. São Paulo: Cosac \& Naify, 2009.

COELHO DE SOUZA, M. O traço e o círculo: o conceito de parentesco entre os Jê e seus antropólogos. Tese (Doutorado em Antropologia Social)-Museu Nacional/Universidade Federal do Rio de Janeiro, Rio de Janeiro, 2002.

COHN, C. Crescendo como um Xikrin: uma análise da infância e do desenvolvimento infantil entre os Kayapó-Xikrin do Bacajá. Revista de Antropologia, São Paulo, v. 43 n. 2. p. 195-222, 2000. 
COIMBRA JR., C. E. A. et al. The Xavánte in transition: health, ecology and bioanthropology in Central Brazil. Ann Arbor: University of Michigan Press, 2002 .

CROCKER, W. H.; CROCKER, J. G. Os Canelas: parentesco, ritual e sexo em uma tribo da chapada maranhense. Rio de Janeiro: Museu do Índio, 2009.

DAMATTA, R. Mito e linguagem social. Rio de Janeiro: Tempo Brasileiro, 1970.

EID, A. S. F. Romhõsi'wai hawi rowa'õno re ihoimana mono: a criação do mundo segundo os velhos narradores Xavante. Tese (Doutorado em Ciências Sociais)-Instituto de Filosofia e Ciências Humanas, Universidade Estadual de Campinas, Campinas, 2002.

FERNANDES, E. R. Entre cosmologias, estratégias e performances: incursões xavante à Funai. Dissertação (Mestrado em Antropologia)-Instituto de e Ciências Sociais, Universidade de Brasília, Brasília, 2005.

FERREIRA, A. A. Estado nutricional e fatores associados ao crescimento de crianças indigenas xavante, mato grosso. Dissertação (Mestrado em Saúde Pública)-Escola Nacional de Saúde Pública, Fundação Oswaldo Cruz, Rio de Janeiro, 2009.

GIACCARIA, B.; HEIDE, A. A'uwê Uptabi - Xavante: povo autêntico pesquisa histórico etnográfica. 2. ed. São Paulo: Salesiana D. Bosco, 1984.

GRAHAM, L. R. Performing dreams: discourses of immortality among the Xavante of central Brazil. Austin: University of Texas Press, 1995.

LÉVI-STRAUSS, C. Mitológicas I: o cru e o cozido. São Paulo: Cosac \& Naify, 2004.

LOPES DA SILVA, A. Nomes e amigos: da prática xavante a uma reflexão sobre os Jê. Tese (Doutorado em Antropologia Social)-Faculdade de Filosofia, Letras e Ciências Humanas, Universidade de São Paulo, São Paulo, 1980.

LOPES DA SILVA, A. A expressão mítica da vivência histórica: tempo e espaço na construção da identidade Xavante. In: ANUÁRIO antropológico 1982. Rio de Janeiro: Tempo Brasileiro, 1984. p. 200-213. 
LOPES DA SILVA, A. Social practice and ontology in Akwe-Xavante naming and myth. Ethnology, v. 28, n. 4, p. 331-341, 1989.

MAYBURY-LEWIS, D. A sociedade xavante. Rio de Janeiro: Francisco Alves, 1984.

MELATTI, J. C. Ritos de uma tribo timbira. São Paulo: Ática, 1978.

ROCHA, R. P. A questão do gênero na etnologia jê: a partir de um estudo sobre os Apinajé. Dissertação (Mestrado em Antropologia)-Instituto de Filosofia e Ciências Humanas, Universidade Estadual de Campoinas, Campinas, 2001.

SAUMA, J. F. Encontros cartografados: reflexões sobre encontros entre meninos e educadores de rua. Cadernos de Campo, São Paulo, n. 14/15, p. 41-63, 2007.

SEEGER, A. Os índios e nós: estudos sobre sociedades tribais brasileiras. Rio de Janeiro: Campus. 1980.

TURNER, T. Social body and embodied subject: bodiliness, subjectivity and sociality among the Kayapó. Cultural Anthropology, v. 10, n. 2, p. 143-79. 1995.

VIDAL, L. Morte e vida de uma sociedade indígena brasileira. São Paulo: Hucitec; Edusp, 1977.

VIDAL, L. A pintura corporal e a arte gráfica entre os Kayapó-Xikrin do Cateté. In: VIDAL, L. B. (Org.). Grafismo indigena. São Paulo: Studio Nobel; Fapesp; Edusp, 2000. p. 143-190.

VIVEIROS DE CASTRO, E. Filiação intensiva e aliança demoníaca. Novos Estudos Cebrap, n. 77, p. 91-126, mar. 2007.

WELCH, J.; FERREIRA, A. A.; VENTURA SANTOS, R. Nutrition transition, socioeconomic differentiation, and gender among adult Xavante indians, Brazilian Amazon. Human Ecology, n. 37, p. 13-26, 2009. 